\title{
Impact of physical activity at different levels in heart rhythm in the long term (IMPAR)
}

\author{
Marcio Galindo Kiuchi ${ }^{*}$, Gustavo Ramalho e Silva ${ }^{1}$, Luis Marcelo Rodrigues Paz ${ }^{1}$, Gladyston Luiz Lima Souto ${ }^{1}$ and Shaojie Chen $^{2,3}$ \\ ${ }^{1}$ Division of Cardiac Surgery and Artificial Cardiac Stimulation, Department of Medicine, Hospital e Clinica Sao Goncalo, Sao Goncalo, RJ, Brazil \\ ${ }^{2}$ Department of Cardiology, Shanghai First People's Hospital, Shanghai Jiao Tong University School of Medicine, Shanghai, China \\ ${ }^{3}$ Fellowship of European Heart Rhythm Association / European Society of Cardiology, Department of Cardiology, Elisabethinen University Teaching Hospital \\ Linz, Linz, Austria
}

\begin{abstract}
Introduction: Healthy adults who are the least fit have a mortality risk that is 4.5 times. Surprisingly an individual's physical exercise level was one of the most important predictors of death than well-known risk factors such as smoking, hypertension, high cholesterol, and diabetes. Studies underscore the fact that fitness and daily activity levels have a strong influence on the incidence of heart disease and overall mortality. Based on these facts we observed several individuals assess how far physical exercise can be beneficial in the long term.

Aim: To evaluate the impact of physical activity at different levels in heart rhythm in the long term.

Methods and results: We enrolled 261 subjects, excluding 54 individuals, and conducted an observational retrospective study in 207 subjects, who related to practice regular running during all their lives. We take into account, most specifically the running practiced four to five days per week of different levels, for the last 3 years, except during periods of lesions or diseases. As a routine of our Department, the results of baseline tests are stored on a computer, e.g., 24-hour-Holter monitoring, 24-hour ABPM, blood tests, cardiac magnetic resonance. The subjects were divided into 3 groups, according to the running distance covered, measured in kilometers $(\mathrm{Km})$, during one week: $\leq 48 \mathrm{~km} /$ week $(\mathrm{n}=85),>48$ and $\leq 84 \mathrm{~km} /$ week $(\mathrm{n}=69)$, and $>84$ and $\leq 168 \mathrm{Km} /$ week $(\mathrm{n}=53)$. We observed from the 85 subjects that run $\leq 48$ $\mathrm{km} /$ week $(41.8 \pm 7.5 \mathrm{Km} /$ week) only $12(14 \%)$ had pacemaker implantation indication, while from the 69 individuals that run $>48$ and $\leq 84 \mathrm{~km} /$ week $(75.7 \pm 10.1$ $\mathrm{Km} /$ week), 20 (29\%) of them received pacemaker implantation indication, and from the 53 subjects that run $>84$ and $\leq 168 \mathrm{Km} /$ week $(152.2 \pm 16.4 \mathrm{Km} /$ week), 37 (70\%) of them had pacemaker implantation indication at some time during the life. The comparisons between these groups were significant statistically: $41.8 \pm 7.5$ vs. $75.7 \pm 10.1 \mathrm{~km} /$ week, $\mathrm{P}=0.0268 ; 41.8 \pm 7.5$ vs. $152.2 \pm 16.4 \mathrm{Km} /$ week, $\mathrm{P}<0.0001 ; 75.7 \pm 10.1$ vs. $152.2 \pm 16.4 \mathrm{Km} /$ week, $\mathrm{P}<0.0001$
\end{abstract}

Conclusions: In conclusion, subjects who are exposed to a higher weekly running training load and consequently throughout life, appear to be more prone to the onset of cardiac arrhythmia, which is gravest, requiring the permanent pacemaker implantation.

\section{Introduction}

Approximately 250 thousand deaths per year in the United States are attributable to an absence of regular physical activity. Moreover, studies that followed big groups of persons for several years have recognized the protecting effects of physical exercise for a number of non-cardiovascular chronic diseases, such as non-insulin-dependent diabetes, hypertension, osteoporosis, and colon cancer [1]. In contrast, we see a greater frequency of cardiovascular events and a higher death rate in those individuals with low levels of physical exercises [1,2]. Even midlife increases in physical activity, through a change in occupation or recreational activities, are associated with a decrease in mortality [3]. It does not take a marathoner or an elite athlete to arise significant benefits from physical exercise. Actually, the Surgeon General's physical activity recommendations seem unexpectedly mild. One cause for this is that the maximum gains in terms of mortality are reached when a person ceases to be sedentary to become moderately active [4]. Studies show that less is gained when an individual goes from being moderately active to very active. In a study performed by US veterans, subjects were categorized into 5 groups according to good physical condition level. The major gains regarding mortality were reached between the lowest good physical condition level group and the following lowest fitness cluster. Investigators studied 6213 men over a 6-year period and compared the risks of death (after allowing for age adjustment) by gradients of physical activity [5]. Healthy adults who are the least fit have a mortality risk that is 4.5 times. Astonishingly an individual's fitness level was a more important predictor of death than established risk factors for instance smoking, hypertension, high cholesterol, and diabetes. Studies underscore the fact that fitness and daily activity levels have a strong influence on the incidence of heart disease and overall mortality. Based on these facts we observed several individuals assess how far physical exercise can be beneficial in the long term.

Correspondence to: Dr.Márcio Galindo Kiuchi, Division of Cardiac Surgery and Artificial Cardiac Stimulation, Department of Medicine, Hospital e Clínica São Gonçalo, Rua Cel. Moreira César, 138 - Centro, São Gonçalo, Rio de Janeiro 24440-400, Brazil; Tel: +55 (21) 26047744; Fax: +55 (21) 26047744; E-mail: marciokiuchi@gmail.com

Key words: physical activity; running; cardiac arrhythmias; pacemaker; structurally normal heart; cardiac magnetic resonance

Received: July 18, 2016; Accepted: August 13, 2016; Published: August 16, 2016 


\section{Methods}

\section{Study subjects}

In this study, we enrolled 261 subjects, excluding 54 individuals, and conducted an observational retrospective study in 207 subjects, who related to practice regular running during all their lives. We take into account, most specifically the running practiced four to five days per week at different levels, for the last 3 years, except during periods of lesions or diseases (Figure 1). This study was conducted in agreement with the Helsinki Declaration and approved by the local Ethics Committee. All patients gave written informed consent before inclusion. In the present study, we aim to evaluate the impact of physical activity at different levels in heart rhythm in the long term. This study was steered in the state of Rio de Janeiro, Brazil in the Hospital e Clinica Sao Goncalo. The subjects were evaluated from January 2014 to January 2016 from a selection of our database that counts on patients derived from Cardiology and Internal Medicine Services of the same hospital, from our offices, and the health network of the county. As a routine of our Department, the results of baseline tests are stored on a computer, e.g: 24-hour-Holter monitoring, 24-hour ABPM, blood tests, cardiac magnetic resonance, because these patients may develop arrhythmias and require treatments with pacemakers and defibrillators implants. The subjects were divided into 3 groups, according to the running distance covered, measured in kilometers $(\mathrm{Km})$, during one week: $\leq 48 \mathrm{~km} /$ week $(\mathrm{n}=85),>48$ and $\leq 84 \mathrm{~km} /$ week $(\mathrm{n}=69)$, and $>84$ and $\leq 168 \mathrm{Km} /$ week $(\mathrm{n}=53)$. The individuals who had the combination of the following criteria were consecutively enrolled: (i) practice running regularly engaging in one of the three aforementioned groups; (ii) age between 45 and 75 years; (iii) structurally normal heart to CRM, without heart failure, ischemia, fibrosis area or any other disease, requested at the office visit; (iv) heart rhythm recorded by the 24-hourHolter monitoring at baseline prompted at the office visit; (v) be able to read, understand and sign the informed consent form.

Subjects with any of the following criteria were excluded: (i) pregnancy; (ii) valvular disease with significant hemodynamic repercussions; (iii) myocardial infarction, unstable angina, stroke or transient ischemic attack previously; (iv) psychiatric disease; (v) atrial fibrillation or/and atrial flutter, atrial or ventricular tachycardia, atrial or premature ventricular complexes higher than $25 \%$ during 24 hours,.

\section{4-hour-Holter monitoring}

All the subjects underwent a 24-hour-Holter monitoring (Galix Biomedical Instrumentation, Florida, USA) at baseline. A 3-channel recorder was used to record the electrocardiographic traces, calculate the minimum, average and maximum $\mathrm{HR}$.

\section{Cardiac magnetic resonance}

CMR was performed in all individuals at baseline and 6 months after RSD using a $1.5 \mathrm{~T}$ Achieva magnetic resonance images (MRI) scanner (Philips Healthcare, Best, the Netherlands) or 1.5 T Siemens Symphony or a 1.5 T Siemens Aera MRI system (Siemens Healthcare Sector, Erlangen, Germany). Cine images were picked up using a secure steady-state free precession sequence during breath-holds of $\sim 10-15$ s using VCG gating with patients being placed in the supine position. Whole-heart overage from apex to the base was performed as previously reported [6]. Furthermore, late gadolinium enhancement (LGE) has been performed in all subjects to evaluate the impact of RSD on scar tissue. Late gadolinium-enhanced imaging was executed 10-15 min after injection of $0.2 \mathrm{mmol} / \mathrm{kg}$ gadolinium DTPA using an inversion-recovery 3D spoiled gradient echo sequence. The pre-pulsedelay was individually adjusted according to a pre-pulse-delay finder (Look-Locker sequence). All CMR examinations were performed by operators, who were blinded to patient's treatment and time of the measurement.

\section{Cardiac magnetic resonance analysis}

Left ventricular mass (LVM) measurements and ejection fraction: CMRI analyses were performed according to the recommendations of the task force for post-processing of the Society for Cardiovascular MR [7]. Offline CMR analyses were performed using the software Qmass MR Enterprise Solution (version 7.4, Medis, the Netherlands). Endocardial and epicardial borders were traced automatically and revised manually at end-diastole and end-systole, even though the papillary muscles were left out from LVM to reach better reproducibility [8]. Left ventricular volumes and mass were calculated using the summation of slices method [9]. The left ventricular end-systolic (LVESVI) and enddiastolic volume index (LVEDVI) were standardized in every patient for sex, height, weight and age, and LVESVI and LVEDVI have been assessed [10]. LVM was then normalized indexing to body surface area

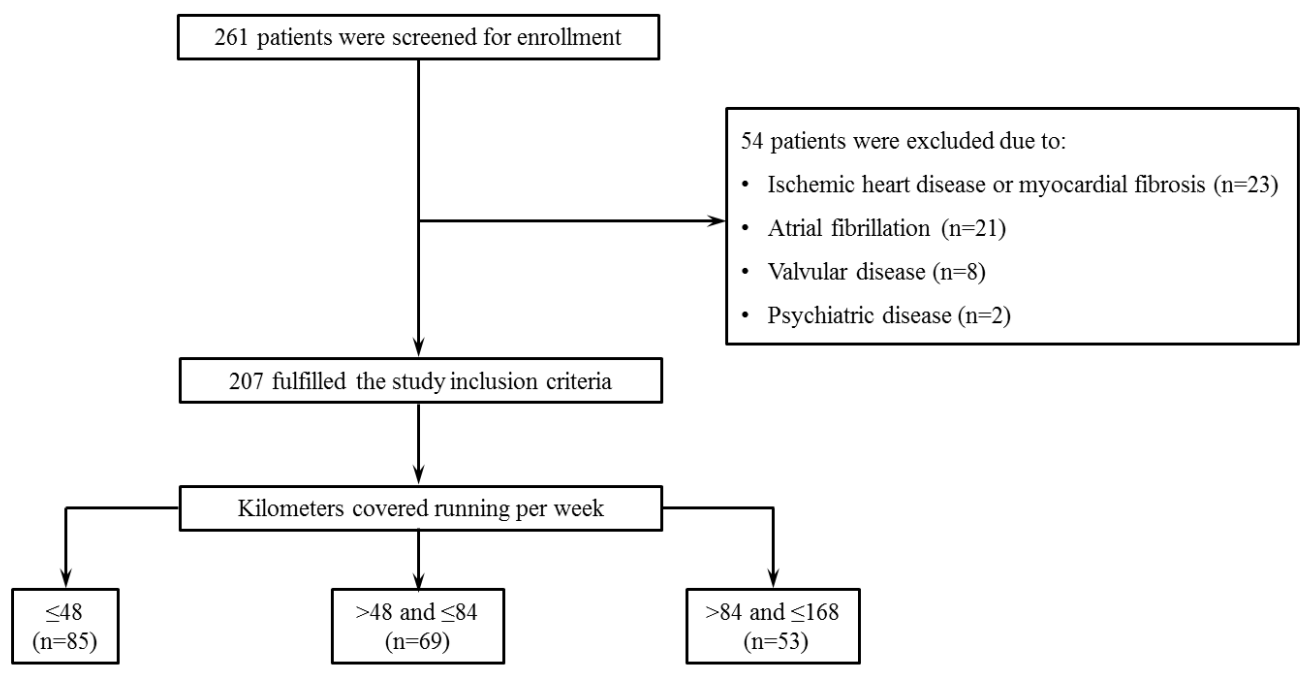

Figure 1. The flow chart of the study: patient enrolment, Stratification and follow-up. 
$\left(\mathrm{g} / \mathrm{m}^{2}\right)[11]$. We calculated the left ventricular ejection fraction (LVEF) by Simpson's method.

\section{Scar tissue}

To observe the myocardial fibrosis during the time, LGE MRI was applied using the inversion-recovery gradient-echo series. Late gadolinium-enhanced images were counted visually by two experienced observers (blinded to other MRI and clinical data) at the time of the acquisition using a 17-segment model [12]. Each segment was graded using the following-point score: 0 , absence of enhancement; 1 , enhancement of $1-25 \%$ transmurality; 2 , enhancement of $26-50 \%$ transmurality; 3 , enhancement of $51-75 \%$ transmurality, and 4 , enhancement of $76-100 \%$ transmurality [13]. The score per sector was then calculated by dividing total score by 17 referring to the 17 -segment model [12].

\section{Statistical analysis}

The results were expressed as the mean and standard deviation (mean \pm SD) of the mean in the case of normal distribution and as the median with inter-quartile range otherwise. Statistical tests were all two sided. Comparisons between two-paired values were performed by the paired t-test in case of Gaussian distribution or, alternatively, by the Wilcoxon test. Comparisons between more than two-paired values were performed by ANOVA for repeated measures or with Kruskal- Wallis ANOVA as appropriate complemented by a post hoc test. Frequencies were compared with Fisher's exact test. P-values < 0.05 were considered significant. Correlations between two variables were performed by Pearson in the case of Gaussian distribution or, alternatively, with the Spearman correlation test. All statistical analysis was performed using the program Graphpad Prism v 7.0 (Graph pad software, La Jolla, CA, USA).

\section{Results}

\section{Baseline characteristics of patients}

General features of the 207 patients are displayed in (Table 1). They were separated into 3 groups, according to the running distance covered, measured in kilometers (Km), during one week: $\leq 48 \mathrm{~km} /$ week $(\mathrm{n}=85),>48$ and $\leq 84 \mathrm{~km} /$ week $(\mathrm{n}=69)$, and $>84$ and $\leq 168 \mathrm{Km} /$ week $(n=53)$.

\section{Impact of the running at different levels of the heart rate}

At baseline, we can observe that minimum, average and maximum heart rate measured by the 24-hour-Holter monitoring are different between the three groups, being lower in subjects that run $>84$ and $\leq 168 \mathrm{Km} /$ week $(\mathrm{P}<0.0001)$, as shown in (Table 1$)$.

\section{Impact of the running at different levels in the heart rhythm}

We observed from the 85 subjects that run $\leq 48 \mathrm{~km} /$ week $(41.8 \pm$ $7.5 \mathrm{Km} /$ week) only 12 (14\%) had pacemaker implantation indication, while from the 69 individuals that run $>48$ and $\leq 84 \mathrm{~km} /$ week $(75.7$ $\pm 10.1 \mathrm{Km} /$ week), 20 (29\%) of them received pacemaker implantation indication, and from the 53 subjects that run $>84$ and $\leq 168 \mathrm{Km} /$ week $(152.2 \pm 16.4 \mathrm{Km} /$ week), 37 (70\%) of them had pacemaker implantation indication at some time during the life. The comparisons between these groups were significant statistically: $41.8 \pm 7.5$ vs. $75.7 \pm 10.1 \mathrm{~km} /$ week, $\mathrm{P}=0.0268 ; 41.8 \pm 7.5$ vs. $152.2 \pm 16.4 \mathrm{Km} /$ week, $\mathrm{P}<0.0001 ; 75.7 \pm 10.1$ vs. $152.2 \pm 16.4 \mathrm{Km} /$ week, $\mathrm{P}<0.0001$ (Figure 2).

Out of the 12 subjects who developed cardiac arrhythmias and were in the group that ran $41.8 \pm 7.5 \mathrm{Km} /$ week, ten of them developed sinus node disease (SND) and two presented $2^{\text {nd }}$ degree atrioventricular block (AVB) Mobitz II. In the group that ran $75.7 \pm 10.1 \mathrm{Km} /$ week, seven individuals presented SND, eight developed $2^{\text {nd }}$ degree $A V B$ Mobitz II, and five presented $3^{\text {rd }}$ degree AVB. However, the subjects

Table 1. General features of patients at baseline.

\begin{tabular}{|c|c|c|c|c|}
\hline \multirow[t]{2}{*}{ Parameters } & \multicolumn{4}{|c|}{ Kilometers covered running per week } \\
\hline & $\leq 48$ & $>48$ and $\leq 84$ & $>84$ and $\leq 168$ & All P value \\
\hline $\mathrm{N}$ & 85 & 69 & 53 & --- \\
\hline Average, $\mathrm{Km}$ & $41.8 \pm 7.5$ & $75.7 \pm 10.1$ & $152.2 \pm 16.4$ & $<0.0001$ \\
\hline Age (years) & $60.2 \pm 10.5$ & $58.3 \pm 12.2$ & $62.4 \pm 15.1$ & 0.1951 \\
\hline Body mass index, $\mathrm{kg} / \mathrm{m}^{2}$ & $22.1 \pm 2.5$ & $18.0 \pm 3.1$ & $16.2 \pm 2.7$ & $<0.0001$ \\
\hline Male sex $(\%)$ & $54(64 \%)$ & $38(55 \%)$ & $33(62 \%)$ & 0.5370 \\
\hline White ethnicity (\%) & $60(71 \%)$ & $50(72 \%)$ & $42(79 \%)$ & 0.5211 \\
\hline Hypertension & $33(39 \%)$ & $29(42 \%)$ & $16(30 \%)$ & 0.3531 \\
\hline Type 2 Diabetes Mellitus & $39(46 \%)$ & $27(39 \%)$ & $18(34 \%)$ & 0.3653 \\
\hline Antihypertensive & $2.3 \pm 0.5$ & $2.4 \pm 0.5$ & $2.2 \pm 0.4$ & 0.3553 \\
\hline ACE-inhibitors/ARB & $33(39 \%)$ & $29(42 \%)$ & $16(30 \%)$ & 0.3531 \\
\hline Diuretics & $15(18 \%)$ & $14(20 \%)$ & $9(17 \%)$ & 0.8748 \\
\hline 24-hour ABPM, mmHg & $123 \pm 1 / 79 \pm 1$ & $122 \pm 2 / 78 \pm 2$ & $122 \pm 3 / 79 \pm 1$ & $0.3075 / 0.3252$ \\
\hline \multicolumn{5}{|l|}{ 24-hour-Holter monitoring } \\
\hline Minimum heart rate, bpm & $48 \pm 5$ & $44 \pm 4$ & $38 \pm 4$ & $<0.0001$ \\
\hline Average heart rate, bpm & $58 \pm 4$ & $53 \pm 3$ & $48 \pm 3$ & $<0.0001$ \\
\hline Maximum heart rate, bpm & $101 \pm 12$ & $92 \pm 11$ & $81 \pm 7$ & $<0.0001$ \\
\hline Total cholesterol, mg/dL & $123.0 \pm 9.1$ & $125.0 \pm 11.5$ & $121.0 \pm 13.4$ & 0.1451 \\
\hline HDL cholesterol, mg/dL & $73.5 \pm 12.0$ & $77.1 \pm 16.5$ & $76.4 \pm 14.6$ & 0.2571 \\
\hline LDL cholesterol, mg/dL & $78.0 \pm 14.2$ & $75.0 \pm 13.9$ & $74.6 \pm 19.0$ & 0.3471 \\
\hline VLDL cholesterol, mg/dL & $22.3 \pm 1.8$ & $23.4 \pm 3.5$ & $21.9 \pm 6.7$ & 0.1030 \\
\hline Triglycerides, mg/dL & $112.0 \pm 15.3$ & $114.3 \pm 13.2$ & $110.8 \pm 20.4$ & 0.4676 \\
\hline
\end{tabular}

Values are expressed as Mean \pm SD; ABPM, ambulatory blood pressure measurements; ACE, angiotensin-converting enzyme; ARB, angiotensin receptor blocker; HDL, high-density lipoprotein; Km, kilometers; LDL, low-density lipoprotein; N, number of patients; VLDL, very-low-density lipoprotein. 
that $\operatorname{ran} 152.2 \pm 16.4 \mathrm{Km} /$ week, ten have evolved with $\mathrm{SND}$, fifteen with $2^{\text {nd }}$ degree AVB Mobitz II, and twelve with $3^{\text {rd }}$ degree AVB. The comparisons between the set of arrhythmias of these groups showed: $41.8 \pm 7.5$ vs. $75.7 \pm 10.1 \mathrm{~km} /$ week, $\mathrm{P}=0.0066 ; 41.8 \pm 7.5$ vs. 152.2 $\pm 16.4 \mathrm{Km} /$ week, $\mathrm{P}=0.0007 ; 75.7 \pm 10.1$ vs. $152.2 \pm 16.4 \mathrm{Km} /$ week, $\mathrm{P}=0.4723$ (Figure 3).

\section{Cardiac magnetic resonance variables}

Left ventricular measurements and late gadolinium enhancement: There were no significant changes in baseline values comparing the three groups (Table 2). The ischemic segments or LGE score at baseline cannot be compared, because the score per segment remained equal, i.e., absent (Table 2).

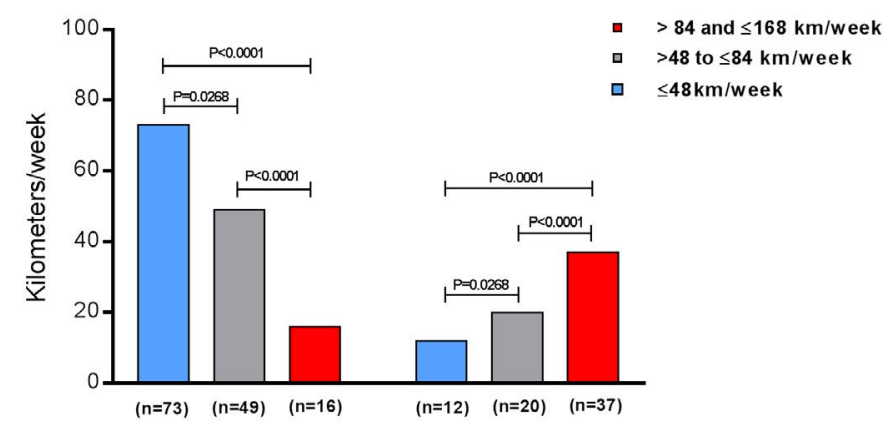

Figure 2. Pacemaker implantation indication due to cardiac arrhythmias appearance in the subjects that were divided into 3 groups, according to the running distance covered, measured in kilometers $(\mathrm{Km})$, per week: $\leq 48 \mathrm{~km} /$ week $(\mathrm{n}=85),>48$ and $\leq 84 \mathrm{~km} /$ week $(\mathrm{n}=69)$, and $>84$ and $\leq 168 \mathrm{Km} /$ week $(\mathrm{n}=53)$.

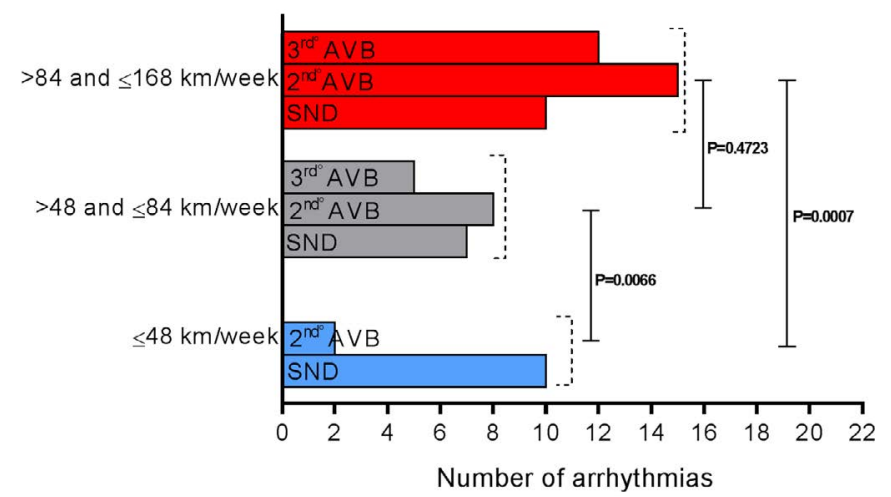

Figure 3. Set of cardiac arrhythmias appearance, classified by type, in the subjects that were divided into 3 groups, according to the running distance covered, measured in kilometers $(\mathrm{Km})$, per week: $\leq 48 \mathrm{~km} /$ week $(\mathrm{n}=85),>48$ and $\leq 84 \mathrm{~km} /$ week $(\mathrm{n}=69)$, and $>84$ and $\leq 168$ $\mathrm{Km} /$ week ( $\mathrm{n}=53$ ); AVB, atrioventricular block; SND, sinus node disease.

Table 2. Cardiac magnetic resonance parameters at baseline.

\begin{tabular}{|c|c|c|c|c|}
\hline \multirow[t]{2}{*}{ Parameters } & \multicolumn{4}{|c|}{ Kilometers covered running per week } \\
\hline & $\leq 48$ & $>48$ and $\leq 84$ & $>84$ and $\leq 168$ & All P value \\
\hline $\mathrm{N}$ & 85 & 69 & 53 & --- \\
\hline LVEDVI, $\mathrm{mL} /{ }^{\mathrm{m}} 2$ & $83.0 \pm 4.0$ & $83.9 \pm 3.0$ & $82.5 \pm 4.1$ & 0.1058 \\
\hline LVESVI, mL/m2 & $27.5 \pm 4.3$ & $28.0 \pm 3.9$ & $28.4 \pm 4.0$ & 0.4412 \\
\hline $\mathrm{LV}$ mass/BSA, $\mathrm{g} / \mathrm{m}^{2}$ & $85.6 \pm 8.3$ & $84.8 \pm 9.0$ & $86.1 \pm 9.8$ & 0.7160 \\
\hline LVEF, \% (Simpson) & $68.9 \pm 10.1$ & $70.2 \pm 13.0$ & $69.5 \pm 12.2$ & 0.7898 \\
\hline Ischemic heart disease & 0 & 0 & 0 & --- \\
\hline Myocardial scar score, $\%$ & 0 & 0 & 0 & --- \\
\hline
\end{tabular}

Values presented as Mean \pm SD; BSA, body surface area; LVEDVI, left ventricular end-diastolic volume index; LVESVI, left ventricular end-systolic volume index; LV, left ventricle; EF, ejection fraction.

\section{Discussion}

In the present study, we demonstrate a higher incidence of cardiac arrhythmias across the time in subjects who practice running in high performance than in ones who train only moderately. As expected, a slower resting heart rate is a marked cardiac adaptation to endurance training and athletes may develop $1^{\text {st }}$ and $2^{\text {nd }}$ degree AVB [14]. Third degree AVB is unusual in athletes and requires a careful evaluation [15]. However, some athletes may develop transient third-degree heart block during sleep when the vagal tone is high. First degree AVB refers to an increase in the atrioventricular conduction time, second to intermittent AVB of electrical conduction from initiating the atrium, and third to complete blockade of the passage of all atrial beats to the ventricles. Several studies suggest that these bradyarrhythmias persevere after the athlete stops physical exercise training $[16,17]$. Persistence of bradycardia and evidence of sinus node defects after the termination of extreme exercise training imply that either endurance athletes have inherently different cardiac electrophysiology previously to physical activity or that prolonged endurance workout remodels the cardiac electrical system. These studies cannot, on the other hand, totally eliminate a persistently more active lifestyle, and consequently more continued exercise working out in the previous endurance athletes.

Even though, atrial fibrillation is the arrhythmia that appears most consistently to be associated with the age-long physical exercise. Atrial flutter is a macro-reentrant atrial arrhythmia from the right side of the heart that most commonly initiates at the cavotricuspid isthmus located in the right atrium. Paroxysmal atrial flutter has been reported in $10 \%$ of former endurance athletes [18], but is often combined with atrial fibrillation in analyses of arrhythmias in athletes [17] ; it was an exclusion criterion in our study because atrial fibrillation decreases the atrial contribution to left ventricular filling and decreases the cardiac output. The decrease in cardiac output can decrease exercise tolerance especially in those with resistance to left ventricular filling such as patients with mitral valve stenosis or left ventricular hypertrophy. Atrial fibrillation can also cause "tachycardia mediated cardiomyopathy" if the ventricular response rate is not controlled [19]. Cardiomyopathy mediated by tachycardia refers to a reversible decrease in the systolic heart function produced by persistently rapid heart rates. A low heart rate and high degree AVB in these subjects can promote the increase in QT interval [20]. Atypical increases in the QT interval may provoke the long QT syndrome, which can produce a phenomenon called " $\mathrm{R}$ over T" causing polymorphic ventricular tachycardia, syncope, and sudden cardiac death. The long QT syndrome does not produce any structural cardiac changes and is the likely cause of many sudden cardiac deaths.

In conclusion, subjects who are exposed to a higher weekly running training load and consequently throughout life, appear to be more prone to the onset of cardiac arrhythmia, which is gravest, requiring 
the permanent pacemaker implantation.

\section{Study limitations}

Our results should be understood with caution given the unblended non-randomized nature of the study. A randomized trial with appropriate concealment of treatment, more patients is required to address the potential benefits and harmful effects of light to exhausting running training.

\section{Funding}

This study was funded by Pace med (US\$100,000).

\section{Acknowledgements}

The authors are grateful to all the participants of this study, particularly, to Pace med by stimulating the development of research and for the technical support.

\section{References}

1. US Public Health Service, Office of the Surgeon General. Physical Activity and Health: A Report of the Surgeon General. Atlanta, GA: US Department of Health and Human Services, Centers for Disease Control and Prevention, National Center for Chronic Disease Prevention and Health Promotion;1996.

2. Pate RR, Pratt M, Blair SN, Haskell WL, Macera CA, et al. (1995) Physical activity and public health. A recommendation from the Centers for Disease Control and Prevention and the American College of Sports Medicine. JAMA 273: 402-407. [Crossref]

3. Paffenbarger RS Jr, Hyde RT, Wing AL, Lee IM, Jung DL, et al. (1993) The association of changes in physical-activity level and other lifestyle characteristics with mortality among men. $N$ Engl J Med 328: 538-545. [Crossref]

4. Myers J (2003) Cardiology patient pages. Exercise and cardiovascular health. Circulation 107: e2-5. [Crossref]

5. Myers J, Prakash M, Froelicher V, Do D, Partington S, et al. (2002) Exercise capacity and mortality among men referred for exercise testing. $N$ Engl J Med 346: 793-801. [Crossref]

6. Kelle S, Roes SD, Klein C, Kokocinski T, de Roos A, et al. (2009) Prognostic value of myocardial infarct size and contractile reserve using magnetic resonance imaging. $\mathrm{J} \mathrm{Am}$ Coll Cardiol 54: 1770-1777. [Crossref]

7. Schulz-Menger J, Bluemke DA, Bremerich J, Flamm SD, Fogel MA, et al.(2013) Standardized image interpretation and post processing in cardiovascular magnetic resonance: Society for Cardiovascular Magnetic Resonance (SCMR) board of trustees task force on standardized post processing. J Cardiovasc Magn Reson 15: 35. [Crossref]
8. Vogel-Claussen J, Finn JP, Gomes AS, Hundley GW, Jerosch- Herold M, et al. (2006) Left ventricular papillary muscle mass: relationship to left ventricular mass and volumes by magnetic resonance imaging. J Comput Assist Tomogr 30: 426-432. [Crossref]

9. Papavassiliu T, Kuh HP, van Dockum W, Hofman MB, Bondarenko O, et al. (2004) The accuracy of one- and two-dimensional algorithms with optimal image plane position for the estimation of left ventricular mass: a comparative study using magnetic resonance imaging. J Cardiovasc Magn Reson 6: 845-854. [Crossref]

10. Maceira AM, Prasad SK, Khan M, Pennell DJ (2006) Normalized left ventricular systolic and diastolic function by steady state free precession cardiovascular magnetic resonance. J Cardiovasc Magn Reson 8: 417-426. [Crossref]

11. Armstrong AC, Gidding S, Gjesdal O,WuC, Bluemke DA, et al.(2012) LV mass assessed by echocardiography and CMR, cardiovascular outcomes, and medical practice. JACC Cardiovasc Imaging 5: 837-848. [Crossref]

12. Cerqueira MD,Weissman NJ, Dilsizian V, Jacobs AK, Kaul S, et al. (2002) Standardized myocardial segmentation and nomenclature for tomographic imaging of the heart. A statement for healthcare professionals from the Cardiac Imaging Committee of the Councilon Clinical Cardiology of the American Heart Association. Circulation 105 539-542.[Crossref]

13. Wu E, Judd RM, Vargas JD, Klocke FJ, Bonow RO, et al. (2001) Visualisation of presence, location, and transmural extent of healed Q-wave and non-Q-wave myocardial infarction. Lancet 357: 21-28. [Crossref]

14. Jensen-Urstad K, Saltin B, Ericson M, Storck N, Jensen-Urstad M (1997) Pronounced resting bradycardia in male elite runners is associated with high heart rate variability. Scand J Med Sci Sports 7: $274-278$.

15. Link MS, Homoud MK, Wang PJ, Estes NA (2002) Cardiac arrhythmias in the athlete: the evolving role of electrophysiology. Curr Sports Med Rep 1: 75-85. [Crossref]

16. Andersen K, Farahmand B, Ahlbom A, Held C, Ljunghall S, et al. (2013) Risk of arrhythmias in 52755 long-distance cross-country skiers: a cohort study. Eur Heart J 34: 3624-3631. [Crossref]

17. Baldesberger S, Bauersfeld U, Candinas R, Seifert B, Zuber M, et al. (2008) Sinus node disease and arrhythmias in the long-term follow-up of former professional cyclists. Eur Heart J 29: 71-78. [Crossref]

18. Hou ZH, Lu B, Gao Y, Jiang SL, Wang Y, et al. (2012) Prognostic value of coronary CT angiography and calcium score for major adverse cardiac events in outpatients. JACC Cardiovasc Imaging 5: 990-999. [Crossref]

19. Gupta S, Figueredo VM (2014) Tachycardia mediated cardiomyopathy: pathophysiology, mechanisms, clinical features and management. Int J Cardiol 172: 40-46. [Crossref]

20. Schwartz PJ, Crotti L, Insolia R (2012) Long-QT syndrome: from genetics to management. Circ Arrhythm Electrophysiol 5: 868-877. [Crossref]

Copyright: (C2016 Kiuchi MG. This is an open-access article distributed under the terms of the Creative Commons Attribution License, which permits unrestricted use, distribution, and reproduction in any medium, provided the original author and source are credited. 